\title{
Mineraçãåo
}

\section{Caracterização de um depósito de rejeitos para o gerenciamento integrado dos resíduos de mineração na região carbonífera de Santa Catarina, Brasil}

\section{Characterization of a coal tailing deposit for integrated mine waste management in the brazilian coal field of Santa Catarina}

Juarez R. do Amaral Filho

Engenheiro Ambiental,

M.Sc, PPGEM/UFRGS.

juarez.amaral@ufrgs.br

Ivo André H. Schneider

Engenheiro de Minas,

Prof. Dr. PPGEM/UFRGS.

ivo.andre@ufrgs.br

Irineu A. S. de Brum

Engenheiro de Minas,

Prof. Dr. DEMET/UFRGS.

irineu.brum@ufrgs.br

Carlos H. Sampaio

Engenheiro de Minas,

Prof. Dr. PPGEM/UFRGS.

sampaio@ufrgs.br

\section{Gerson Miltzarek}

Geólogo, Dr. PPGEM/UFRGS.

gerson.miltzarek@ufrgs.br

\section{Carlos Schneider}

Geólogo, Msc. Carbonífera Criciúma S.A.

schneider@carbocri.com.br

\section{Resumo}

O carvão mineral brasileiro contém altos teores de impurezas (pirita e minerais de rochas sedimentares), sendo necessário seu beneficiamento. Os rejeitos do beneficiamento demandam uma grande área física para a sua disposição, modificam a topografia e geram a drenagem ácida de minas (DAM). O objetivo desse trabalho foi caracterizar um típico depósito de rejeitos na região carbonífera de Santa Catarina, buscando a separação de três frações para uso futuro: (a) uma fração para a geração de energia; (b) uma fração enriquecida em silicatos; e (c) uma fração com alto teor de enxofre. A metodologia do trabalho consistiu na amostragem e caracterização do material. A caracterização incluiu análise granulométrica, estudos densimétricos, medidas do teor de cinzas e enxofre, análise mineralógica por DRX, estudos petrográficos em lupa e medidas de contabilização de ácidos e bases. Os resultados granulométricos indicaram que $68 \%$ do material é composto por partículas grossas, $15 \%$, por partículas finas e $17 \%$, pelo lodo das bacias de sedimentação. Com o beneficiamento gravimétrico dos resíduos é possível uma recuperação teórica do material de 33,7\% para geração de energia e $10,3 \%$ para produção de um concentrado rico em pirita. O material restante, com menor quantidade de enxofre e rico em silicatos, tem seu potencial de geração de acidez reduzido em $60 \%$ e apresenta possibilidade de uso na construção civil.

Palavras-chave: Rejeito de carvão, beneficiamento gravimétrico, meio ambiente. 
methodology consisted in sample collection and characterization of the material. The characterization included particle size analysis, dissymmetric studies, XRD analysis, petrography studies, and acid-base accounting tests. The results showed that $68 \%$ of the material is composed of coarse particles, $15 \%$ of fine particles, and $17 \%$ of slurry from settling ponds. It is possible, by gravimetric concentration of the material, to recover $33.7 \%$ for energetic application and $10.3 \%$ as a pyrite concentrate. The remaining material, with intermediate density, will have a decrease of about $60 \%$ in its net acid generation potential and presents potential for application in civil engineering construction.

Keywords: Coal tailings, coal preparation, environment.

\section{Introdução}

O carvão mineral brasileiro contém altos teores de impurezas (pirita e minerais de rochas sedimentares). Assim, na maioria dos casos, são necessários métodos de concentração para alcançar os parâmetros de operação nas usinas termoelétricas a carvão no Brasil. Por exemplo, o complexo termoelétrico de Jorge Lacerda (SC) aceita produtos com até $43 \%$ de cinzas e $2,3 \%$ de enxofre para geração de energia. Atualmente, cerca de $60-70 \%$ do carvão "run-of-mine" (ROM) de Santa Catarina é disposto em depósitos como rejeitos. Estima-se que existam, aproximadamente, 300 milhões de toneladas de rejeitos de carvão na região sul do país (Figura 1), com significativas quantidades de enxofre. Esses depósitos são a principal fonte de geração da drenagem ácida de mina (DAM), um problema que assola toda a região carbonífera de Santa Catarina e cujo tratamento implica enormes custos.

Para o ano de 2012, está previsto o início da operação de uma usina termoelétrica a carvão com leito fluidizado circulante e capacidade de geração de 440 MW. A Usina Termoelétrica do Extremo
Sul Catarinense - USITESC - aceitará carvões com teores de até $67 \%$ de cinzas e 3,2\% de enxofre. Essa usina prevê, sob ponto de vista de controle ambiental, um sistema de tratamento de emissões atmosféricas, que removerá $99 \%$ do material particulado e $97 \%$ dos gases de enxofre, atendendo, assim, a legislação nacional. Nesse contexto, a recuperação de carvão ROM, na região aumentará. Ainda, empregando técnicas de processamento mineral, parte do material disposto, atualmente, em depósitos de rejeitos poderá ser utilizada para a geração de energia, tanto diretamente, como blendado com carvões com menores teores de cinzas e enxofre.

Importantes trabalhos vêm sendo conduzidos com a intenção de evitar a geração ou tratar a DAM nas regiões carboníferas brasileiras. As principais alternativas consideradas são coberturas secas (Galatto et al., 2007; Schneider 2006; Soares et al., 2008), aditivos alcalinos (Machado \& Schneider, 2008) e tratamento ativo da DAM (Possa \& Santos, 2003; Silveira et al., 2009). Uma outra opção é a concentração/isolamento de sulfetos. De acordo, com Benzaazoua

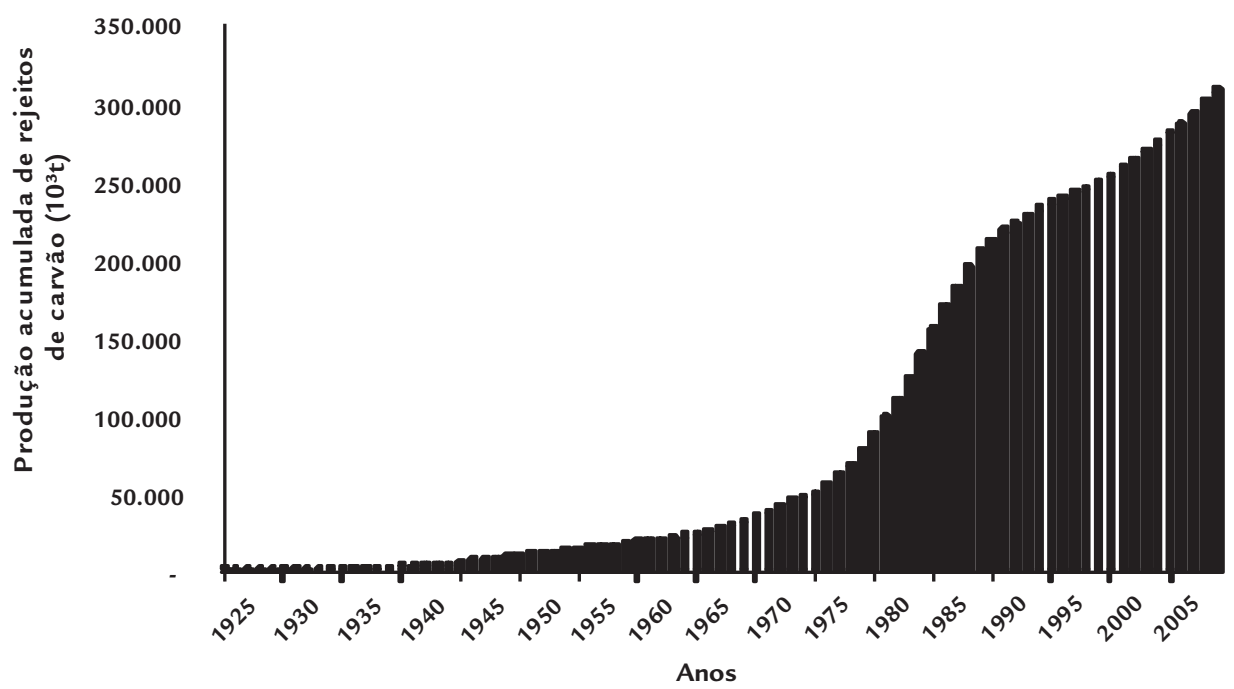

et al. (2008) e Hesketh et al. (2010), com a dessulfurização dos rejeitos de mineração preliminarmente à disposição final, o potencial de geração de acidez e, consequentemente, a lixiviação dos metais são consideravelmente reduzidos, obtendo-se significativos ganhos ambientais e econômicos. Estudos mostram que, por meio da concentração da pirita $\left(\mathrm{FeS}_{2}\right)$, presente em grandes quantidades no carvão catarinense, é possível produzir ácido sulfúrico (atividade que já foi desenvolvida na região entre 1982 e 1993, pela Indústria Carboquímica Catarinense - ICC, e que atualmente se encontra desativada sendo considerada um grande prejuízo ao ciclo produtivo do carvão na região), sulfato férrico (Menezes, 2009), sulfato ferroso (Peterson, 2008; Vigânico, 2009) e pigmentos à base de óxidos de ferro (goetita, hematita e magnetita) (Madeira, 2010; Silva, 2010) com a utilização de processos térmicos e/ou hidrometalúrgicos.

Com o beneficiamento mineral, é possível obter uma fração para aproveitamento energético e outra fração rica em pirita. O restante do material (basicamente siltito e folhelho) pode ser ge-
Figura 1

Produção brasileira acumulada de rejeitos de carvão no período de 1925 a 2009. Fonte: SIECESC (2010). 
renciado de maneira integrada dentro do processo produtivo do carvão e encontrar aplicações. Por exemplo, esse material pode ser empregado como base ou subbase de rodovias (Cañibano et al., 1990) ou em misturas para "backfill" (Benzaazoua et al., 2008). A Figura 2 mostra a atual abordagem de gerenciamento dos rejeitos de carvão (linhas contínuas) e a

Figura 2

Abordagem tradicional e abordagem proposta para o gerenciamento de resíduos de carvão.

\section{Materiais e métodos}

O material estudado foi fornecido pela Carbonífera Criciúma S.A. e é oriundo do Módulo B de rejeitos da Unidade Mineira II - Verdinho (UMII), município de Forquilhinha, SC. Após o processamento mineral do carvão ROM na planta de beneficiamento da UM II, o resíduo é colocado em um depósito de rejeitos que recebe as frações "grossas" $(-50.8 \mathrm{~mm}+2.0 \mathrm{~mm}) \mathrm{e}$ "finas" $(-2.0 \mathrm{~mm}+0,1 \mathrm{~mm})$, bem como o lodo das bacias de sedimentação $(-0,1 \mathrm{~mm})$. Essas bacias são utilizadas para a separação sólido-líquido da água do processo de beneficiamento. A massa estimada de rejeitos, no depósito, é de, aproximadamente, 11 milhões de toneladas. A Figura 3 mostra a vista superior do depósito estudado.

A amostragem foi realizada, em quatro locais, por meio de sondagem rotativa, que atingiu até a base do aterro. As amostras foram misturadas e quarteadas

Figura 3

Vista superior do Módulo $B$ de rejeitos da

UM II - Criciúma S.A (centro) e as bacias de sedimentação utilizadas no tratamento da água de processo (esquerda). abordagem proposta no estudo, com redução na fonte, dentro dos princípios da produção mais limpa e sustentabilidade (linhas tracejadas).

Com base no que foi exposto anteriormente, esse artigo tem, como objetivo, apresentar os resultados de um estudo de caracterização de uma típica pilha de rejeitos localizada na região carbonífera do Estado de Santa Catarina. Os estudos foram realizados visando a concentrar o material em três frações densimétricas distintas, sugerindo as melhores aplicações para cada uma. Os resultados são discutidos levando em conta o contexto regional, bem como os conceitos de produção mais limpa e de desenvolvimento sustentável na mineração.

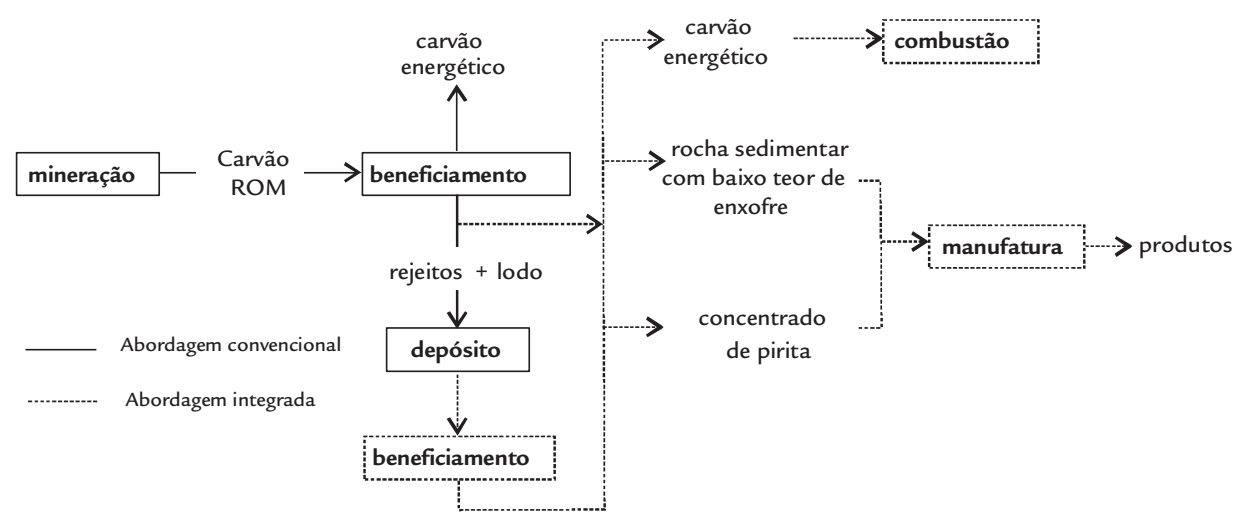

de acordo com a NBR 10.007 (ABNT, 2004). O rejeito foi peneirado e separado nas seguintes frações granulométricas: "grossos" (-50,8 +2,0mm), "finos" $(-2,0$ $+0,1 \mathrm{~mm})$ e "lodo" (- 0,1mm). A fração "grossa" e a fração "fina" foram submetidas a ensaios de afunda-flutua, de acordo com a NBR 8738 (ABNT, 1985), com o objetivo de se obterem a massa de flutuados, nas densidades relativas de 1,5 - 1,7 - 2,0 - 2,2 - 2,4 - 2,8, e a massa de afundados, na densidade relativa de 2,8. Após as análises de afunda-flutua, as frações foram caracterizadas em termos de enxofre total e teor de cinzas. Os teores de enxofre total foram analisados, instrumentalmente, em um equipamento marca Vario Macro, enquanto os resultados de cinzas foram analisados conforme NBR 8289 (ABNT, 1983). Com o resultado dos ensaios, foram construídas as curvas de lavabilidade de Henry-Reinhard, para as duas faixas granulométri- cas consideradas. Foram obtidos, assim, a recuperação teórica de massa, o teor de cinzas e o teor de enxofre do material flutuado ou afundado para cada densidade de corte, bem como a curva de tolerância (também conhecida como NGM - "Near Gravity Material) (Tavares \& Sampaio, 2005).

Análises mineralógicas qualitativas e semiquantitativas adicionais foram realizadas por difração de raios X (DRX) e observação em lupa petrográfica. As análises de DRX foram realizadas em difratômetro de raios $\mathrm{X}$ marca Siemens, modelo D5000. A observação em lupa petrográfica foi realizada com um aumento de 50 vezes em um equipamento Olympus SZ X7. Contabilizou-se a relação ácido-base (ABA) da fração com densidade intermediária pelo procedimento descrito por Sobek (1978), para avaliar o potencial de geração de acidez da amostra.

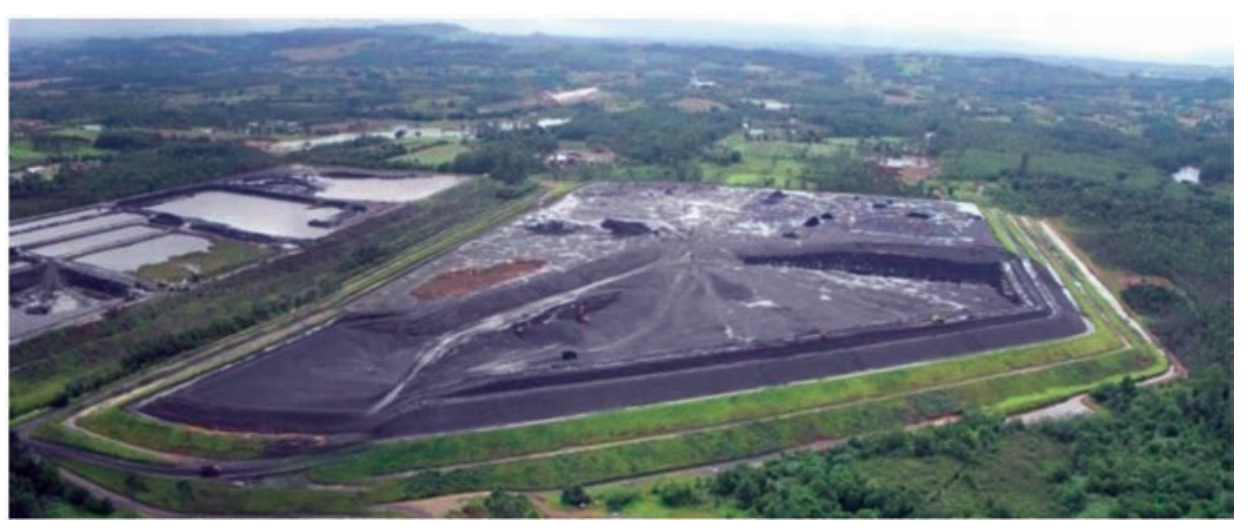




\section{Resultados e discussão}

A análise granulométrica do material teve, por objetivo, quantificar a fração com granulometria entre $-50,8+2,0 \mathrm{~mm}$, que pode ser concentrada por jigagem, a fração com granulometria entre $-2,0+0,1 \mathrm{~mm}$, que pode ser concentrada em um circuito de finos (espirais, mesas e ciclones; alternativamente flotação) e uma fração menor que $0,1 \mathrm{~mm}$, nesse trabalho denominado como "lodo", cuja origem predominante são as bacias de sedimentação. A análise granulométrica mostrou a seguinte distribuição mássica: $68 \%$ de partículas grossas $(-50,8$ $+2,0 \mathrm{~mm}), 15 \%$ de partículas finas $(-2,0$ $+0,1 \mathrm{~mm})$ e $17 \%$ de "lodo" (-0,1mm).

Os ensaios de afunda-flutua e os resultados obtidos nas análises de enxofre total e cinzas permitiram a elaboração das curvas de separabilidade densimétrica para os grossos (Figura 4) e os finos (Figura 5). Na Tabela 1, estão resumidos os resultados analíticos obtidos, bem como os principais componentes mineralógicos identificados por DRX. Os cortes teóricos foram definidos através das curvas de separabilidade densimétrica, permitindo a divisão dos "finos" e dos "grossos" em três frações densimétricas distintas. Observa-se que as frações "grossas" com densidade relativa abaixo de 2,2 e as frações "finas" abaixo de 2,4 apresentam uma maior concentração de matéria carbonosa. As frações com densidades relativas acima de 2,8 apresentam elevados teores de enxofre, devido à presença da pirita. As frações com densidade intermediária apresentaram um alto teor de cinzas e uma significativa predominância do mineral quartzo.
Observa-se que a quantidade de partículas "grossas", com densidades relativas inferiores à 2,2, e a quantidade de partículas "finas", com densidades menores que 2,4 , foram de $8,9 \%$ e $7,8 \%$, respectivamente, com teores de cinzas e enxofre que atenderiam, ou pelo menos ficariam muito próximos, dos parâmetros previstos para a Usina Termoelétrica do Extremo Sul Catarinense - USITESC. Ainda, se essas frações forem blendadas com o "lodo" (- 0,1mm), essa mistura de "finos", "grossos" e "lodo" alcançaria teores de $64,7 \%$ de cinzas e $2,8 \%$ de enxofre, atingindo uma recuperação mássica teórica de $33,7 \%$ do depósito.

Uma outra fração com densidade relativa maior que 2,8 pôde ser processada para a concentração da pirita. Se misturados, os "finos" e os "grossos" apresentariam um produto com cerca de $35 \%$ de enxofre total, aproximadamente $65 \%$ de pirita. A recuperação chegaria a $10,3 \%$ do módulo de rejeitos e esse concentrado poderia ser utilizado para a produção de ácido sulfúrico, sulfato férrico, sulfato ferroso e pigmentos.

$\mathrm{Na}$ Figura 6, são apresentadas as imagens obtidas das diferentes frações em uma lupa petrográfica. Observa-se que, nas faixas menos densas, o material apresenta uma coloração mais escura, devido a uma maior concentração de matéria orgânica. A matéria orgânica, no entanto, apresenta-se de forma disseminada; não tendo se identificado a presença de partículas graúdas de macerais. Nas frações com densidade intermediária a coloração é amarronzada e fosca, caracterizando a
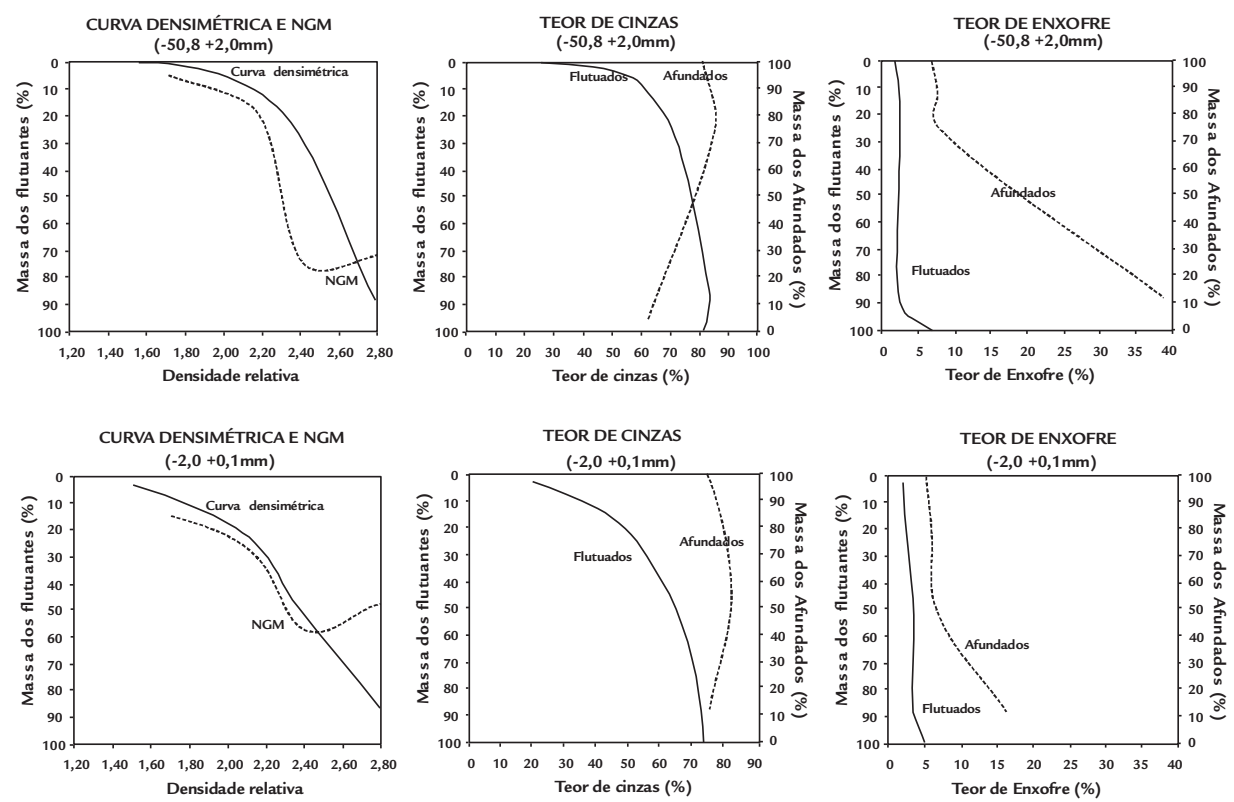

predominância de minerais inorgânicos, que compõem a rocha sedimentar da jazida (basicamente folhelhos e siltitos). Finalmente, na densidade relativa superior a 2,8, o material apresenta, claramente, uma elevada concentração do mineral pirita, presente, tanto na forma disseminada, como em nódulos.

Levando-se em consideração que o módulo de rejeitos possua uma massa de resíduos de 11 milhões de toneladas e a possibilidade de separação da fração energética e da fração pirítica, a massa total no módulo B pode ser reduzida, teoricamente, em até $44 \%$ (4.840.000 t). O restante do material, aproximadamente $56 \%(6.160 .000$ t), consistirá em um material, ambientalmente, menos agressivo.

A redução no teor de enxofre refletirá, diretamente, no potencial de geração de acidez. O teor de enxofre total do módulo passará de $5,9 \%$ para $2,3 \%$. Os resultados dos testes de contabilização de ácidos e bases (Sobek, 1978) demonstraram valores iniciais de NNP (potencial de geração de acidez líquido) de $-184,4 \mathrm{~kg}$ $\mathrm{CaCO}_{3} / \mathrm{t}$ (considerando todo o depósito) e valores finais de $-71,8 \mathrm{~kg} \mathrm{CaCO}_{3} / \mathrm{t}$. Com isso, a acidez e a concentração de metais na DAM serão reduzidas e os custos de tratamento da drenagem também diminuirão. De acordo com investigações preliminares, estudos poderiam ser iniciados, para a utilização dessa fração, em novos mercados consumidores, como, por exemplo: aterros, produção de peças cerâmicas, agregados finos e grossos para concretos e rochagem ("rock for crops”).

\section{Figura 4}

Curvas de separabilidade densimétrica da fração grossa $(-50,8+2,0 \mathrm{~mm})$ construídas a partir das análises de afunda-flutua com meios densos orgânicos.

\section{Figura 5}

Curvas de separabilidade densimétrica da fração fina $(-2,0+0,1 \mathrm{~mm})$ construídas a partir das análises de afunda-flutua com meios densos orgânicos. 
Tabela 1

Resultados analíticos do rejeito de carvão por faixa densimétrica e faixa granulométrica.

\begin{tabular}{|c|c|c|c|c|c|c|}
\hline $\begin{array}{c}\text { Densidade } \\
\text { relativa }\end{array}$ & $\begin{array}{c}\text { Granulometria } \\
(\mathrm{mm})\end{array}$ & $\begin{array}{c}\text { Enxofre } \\
(\%)\end{array}$ & $\begin{array}{c}\text { Cinzas } \\
(\%)\end{array}$ & $\begin{array}{c}\text { Massa } \\
(\%)\end{array}$ & $\begin{array}{c}\text { Resultados DRX. } \\
\text { Análise semiquantitativa dos } \\
\text { compostos cristalinos (\%) }\end{array}$ & $\begin{array}{l}\text { Possíveis } \\
\text { Produtos }\end{array}$ \\
\hline$-2,2$ & $-50,8+2,0$ & 2,4 & 62,3 & 8,9 & $\begin{array}{c}\text { quartzo(58), gipso(14), caulinita(12), } \\
\text { jarosita (10), illita (6) }\end{array}$ & \multirow{2}{*}{$\begin{array}{l}\text { carvão } \\
\text { energético }\end{array}$} \\
\hline$-2,4$ & $-2,0+0,1$ & 3,6 & 65,8 & 7,8 & $\begin{array}{c}\text { quartzo }(53, \text { jarosita }(16), \text { gipso(14) } \\
\text { caulinita (10), illita (7) }\end{array}$ & \\
\hline$+2,2-2,8$ & $-50,8+2,0$ & 2,2 & 87,2 & 50,7 & $\begin{array}{c}\text { quartzo(75), plagioclásio(8), illita } \\
\text { (5), feldspato alcalino (4), gipso (4), } \\
\text { caulinita (4) }\end{array}$ & \multirow{2}{*}{$\begin{array}{c}\text { materiais } \\
\text { para } \\
\text { construção } \\
\text { civil, } \\
\text { rochagem }\end{array}$} \\
\hline$+2,4-2,8$ & $-2,0+0,1$ & 3,7 & 85,5 & 5,3 & $\begin{array}{c}\text { quartzo(63), gipso(17), caulinita (6), } \\
\text { jarosita (6), feldspato alcalino (5), } \\
\text { illita (3) }\end{array}$ & \\
\hline$+2,8$ & $-50,8+2,0$ & 38,4 & 65,7 & 8,5 & $\begin{array}{l}\text { pirita(69), quartzo(18), } \\
\text { gibbsita (13) }\end{array}$ & \multirow{2}{*}{$\begin{array}{l}\text { ácido } \\
\text { sulfúrico } \\
\text { sulfato } \\
\text { férrico, } \\
\text { sulfato } \\
\text { ferroso e } \\
\text { pigmentos }\end{array}$} \\
\hline$+2,8$ & $-2,0+0,1$ & 16,1 & 75,6 & 1,8 & $\begin{array}{c}\text { quartzo(40); pirita(19), } \\
\text { plagioclásio (10), jarosita (8), } \\
\text { gibbsita (7), gipso (6), caulinita (6), } \\
\text { feldspato alcalino (4) }\end{array}$ & \\
\hline $\mathrm{N} / \mathrm{D}$ & $-0,1$ & 2,6 & 65,5 & 17,0 & $\begin{array}{l}\text { quartzo(54), gipso (19), jarosita (14), } \\
\text { caulinita (13) }\end{array}$ & $\begin{array}{l}\text { carvão } \\
\text { energético }\end{array}$ \\
\hline
\end{tabular}

Figura 6

Imagens realizadas em lupa petrográfica das frações "grossas" $(-50,8+2,0 \mathrm{~mm})$ e "finas" $(-2,0+0,1 \mathrm{~mm})$ obtidas nos ensaios densimétricos:

(A) Amostra da fração "grossa" flutuada na densidade relativa de 2,2.

(B) Amostra da fração "fına" flutuada na densidade relativa de 2,4.

(C) Amostra da fração "grossa" afundada em 2,2 e flutuada em 2,8.

(D) Amostra da fração "fina" afundada em 2,4 e flutuada em 2,8.

(E) Amostra da fração "grossa" afundada em 2,8. (F) Amostra da fração "fina" afundada em 2,8.
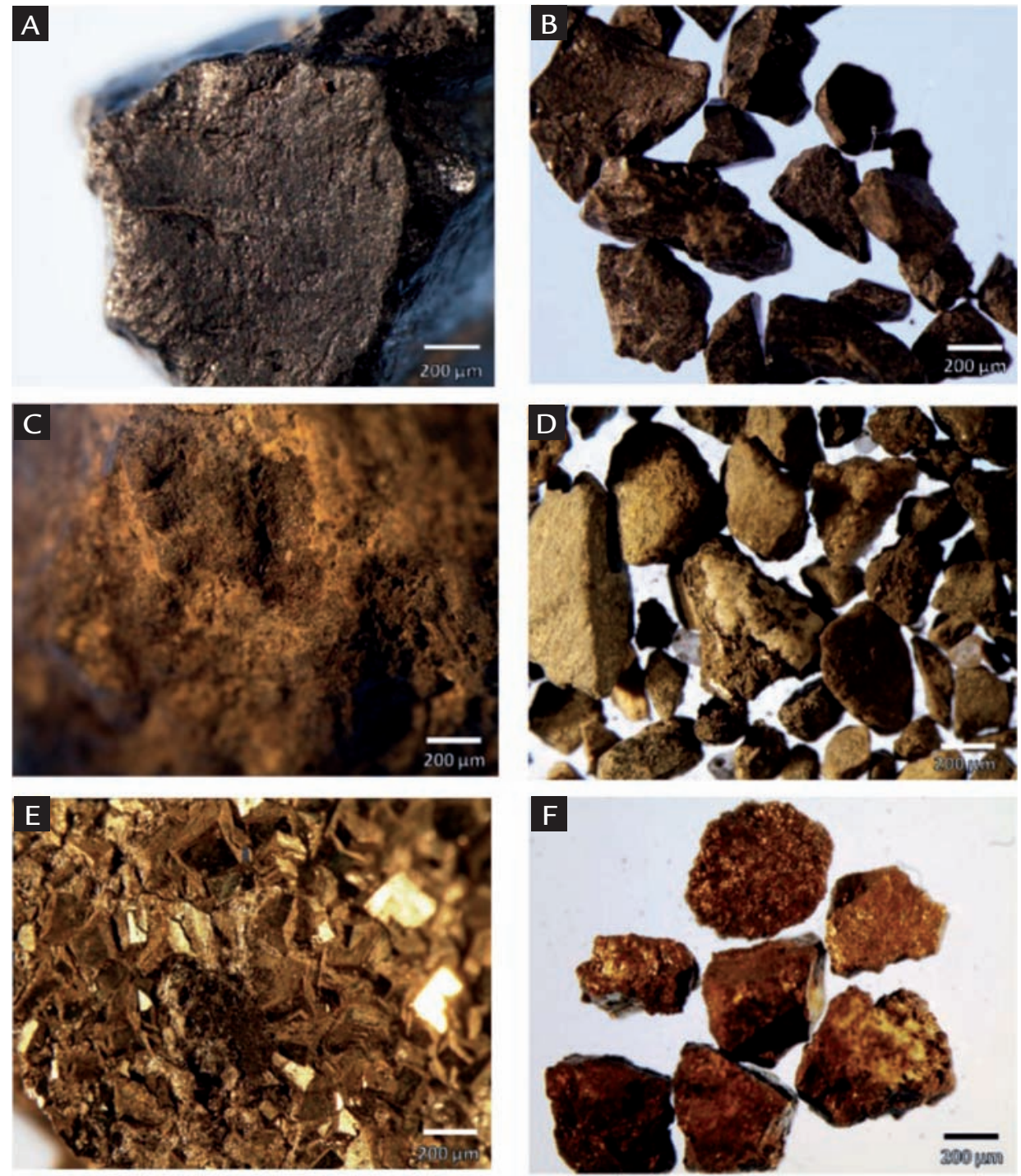


\section{Conclusões}

O setor carbonífero de Santa Catarina, por meio das indústrias, órgãos governamentais e instituições de pesquisa, está engajado em recuperar a região de toda a poluição causada por décadas de exploração insustentável de carvão mineral. Os principais esforços têm sido em dispor, adequadamente, os resíduos de carvão e tratar a DAM por meio de tratamento físico-químico, soluções consideradas de fim de tubo. Entretanto parte dos problemas ambientais pode ser resolvida aproveitando os resíduos

\section{Agradecimentos}

Os autores são gratos ao CNPQ, Rede Carvão, UFRGS e Carbonífera Cri- da mineração como matéria-prima para outras atividades industriais. A região apresenta uma economia diversificada e em expansão (incluindo agricultura, cerâmica, construção civil e outras indústrias em geral), que, através de pesquisa e desenvolvimento, poderia assimilar parte dos materiais descartados. Apesar do potencial de aproveitamento, poucos estudos foram conduzidos, no intuito de recuperar os materiais em depósitos de rejeito da região. Assim, não existem plantas de beneficiamento adaptadas conforme a abordagem dada nesse trabalho. Contudo, através de investimentos em inovação tecnológica, novos processos e produtos poderão ser gerados, promovendo o desenvolvimento econômico e social na região. $\mathrm{O}$ presente trabalho demonstra que, com gerenciamento integrado do carvão mineral e dos rejeitos de beneficiamento, as indústrias carboníferas podem aumentar a vida dos empreendimentos mineiros e reduzir, ou mesmo eliminar, os passivos ambientais. ciúma S.A., pelo apoio técnico e financeiro para a realização do trabalho.

\section{Referências}

ASSOCIAÇÃO BRASILEIRA DE NORMAS TÉCNICAS - ABNT. Carvão mineral - determinação do teor de cinza. NBR 8289. Rio de Janeiro, 1983. 4p.

ASSOCIAÇÃO BRASILEIRA DE NORMAS TÉCNICAS - ABNT. Carvão mineral - ensaios densimétricos. NBR 8738. Rio de Janeiro, 1985. 9p.

ASSOCIAÇÃO BRASILEIRA DE NORMAS TÉCNICAS - ABNT. Amostragem de resíduos sólidos. NBR 10.007. Rio de Janeiro, 2004. 21p.

BENZAAZOUA M., BUSSIÈRE B., DEMERS I., AUBERTIN M., FRIED E., BLIER A. Integrated mine tailings management by combining environmental desulphurization and cemented paste backfill: Application to mine Doyon, Quebec, Canada. Minerals Engineering, v.21, p. 330-340, 2008.

CAÑIBANO, J.G., GARCIA, M., VALCARCE J.A.F. Construction of a road base using coal wastes stabilized with cement. In: Reclamation, Treatment and Utilization of Coal Mining Wastes. p. 17-23, 1990, Glasgow, UK.

GALATTO, S.L., LOPES, R.P., BACK, A.J., BIF, D.Z., SANTO, E.L. Emprego de coberturas secas no controle da Drenagem Ácida de Mina - Estudos em campo. Engenharia Sanitária e Ambiental, v. 12, n. 2, p. 229-236, 2007.

HESKETH, A.H., BROADHURST, J.L., HARRISON, S.T.L. Mitigating the generation of acid mine drainage from copper sulfide tailings impoundments in perpetuity: A case study for an integrated management strategy. Minerals Engineering, v. 23, p. 225-229, 2010.

MACHADO, L.A., SCHNEIDER, I.A.H. Ensaios estáticos e cinéticos para a prevenção da geração de drenagem ácida de minas da mineração de carvão com escória de aciaria. REM - Revista Escola de Minas, v. 61, p. 329-335, 2008.

MADEIRA, V.S. Aproveitamento de resíduos da mineração de carvão para a fabricação de produtos com elevado valor agregado. Florianópolis: Universidade Federal de Santa Catarina, 2010. (Tese de Doutorado).

MENEZES, J.C.S.S. Produção de coagulantes férricos na mineração de carvão. Porto Alegre: Universidade Federal do Rio Grande do Sul, 2009. (Tese de Doutorado).

PETERSON, M.Produção de sulfato ferroso a partir da pirita: desenvolvimento sustentável. Florianópolis: Universidade Federal de Santa Catarina. 2008. (Tese de Doutorado).

POSSA, M.V., SANTOS, M.D.C. Tratamento de drenagem ácida de mina por processo de neutralização controlada. Rio de Janeiro: CETEM/MCT, 2003, 21p.

SCHNEIDER, C.H. Controle da drenagem ácida de minas na mineração de carvão de Santa Catarina: caso da mina UM II - Verdinho. Porto Alegre: Universidade Federal do Rio Grande do Sul, 2006. (Dissertação de Mestrado).

SILVA, R.A. Recuperação hidrometalúrgica de metais da drenagem ácida de minas por precipitação seletiva. Porto Alegre: Universidade Federal do Rio Grande do Sul, 2010. (Tese de Doutorado). 
SILVEIRA, A.N., SILVA, R., RUBIO, J. Treatment of acid mine drainage (AMD) in South Brazil: comparative active processes and water reuse. International Journal of Mineral Processing, v.93, n.2, p. 103-109, 2009.

SOARES, P.S.M., SANTOS, M.D.C., POSSA, M.V. Carvão brasileiro: tecnologia e meio ambiente. Rio de Janeiro: CETEM/MCT, 2008, 300p.

SOBEK, A.A., SCHULLER, W.A., FREEMAN, J.R., SMITH, R.M. Field and laboratory methods applicable to overburden and minesoils, EPA 600/2-78-054, 1978. 203p.

TAVARES, L.M.M. E SAMPAIO, C.H. Beneficiamento gravimétrico. Porto Alegre: Editora da UFRGS, 2005. 601p.

VIGANICO E.M. Produção de sulfato ferroso a partir de rejeitos de carvão. Porto Alegre: Universidade Federal do Rio Grande do Sul, 2009. (Dissertação de Mestrado).

Artigo recebido em 03 de fevereiro de 2011. Aprovado em 28 de março de 2013. 